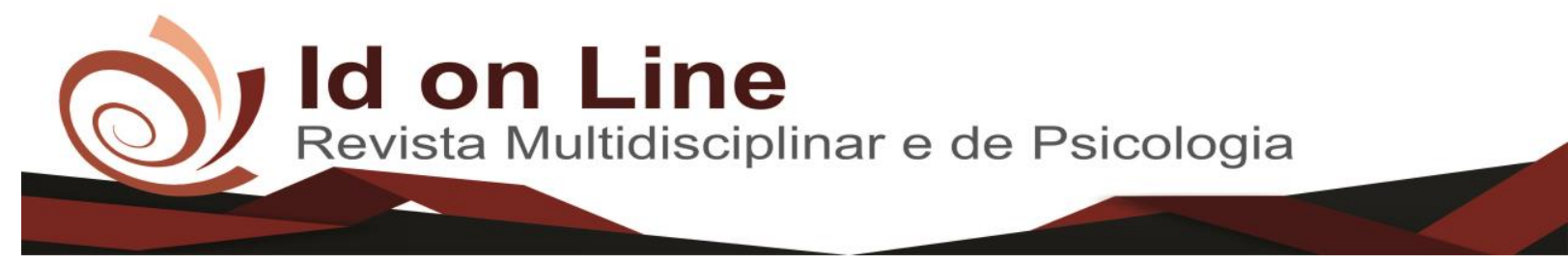

Relato de Caso

\title{
A Relevância da Equoterapia no Desenvolvimento de Crianças com Necessidades Especificas no Âmbito Escolar
}

\author{
Edmila Lima de Barros ${ }^{1}$; Maria do Socorro Cecílio Sobral ${ }^{2}$
}

\begin{abstract}
Resumo: O presente estudo tem como objetivo analisar e refletir os benefícios da equoterapia. E como base teórica os estudos de Cirillo (1991:01),"Equoterapia é um tratamento para reeducação motora e mental, através da prática de atividades equestres e técnicas de equitação". Sendo, o propósito deste artigo refletir acerca do desenvolvimento motor, psicossociais e cognitivos da criança ou praticante dessa técnica de reabilitação. O presente trabalho se constitui em um estudo de caso, de natureza qualitativa no qual foi abordado sobre a Equoterapia , história, benefícios, no desenvolvimento da criança com necessidades educativas específicas enquanto recurso e técnica de reabilitação, bem como, através dos dados coletados a partir do questionário aplicado aos respondentes do espaço escolar, familiar e terapêutico os quais afirmaram que num período de um ano e três meses da equoterapia ocorreram resultados de melhorias da atenção, concentração; relações sociais na escola com professores e colegas; motricidade e interação social do praticante. Aspectos que são de suma importância no rendimento escolar.
\end{abstract}

Palavras - Chave: Equoterapia, Necessidades Específicas, Âmbito Escolar.

\section{The Relevance of Equine Therapy in the Development of Children with Specific Needs in the School Environment}

\begin{abstract}
The present study aims to analyze and disseminate the benefits of equine therapy. And as a theoretical basis the studies of Cirillo (1991: 01), "Equine is a treatment of motor and mental reeducation, through the practice of equestrian activities and riding techniques". The purpose of this article is to reflect on the motor, psychosocial and cognitive development of the child or the practitioner of this rehabilitation technique. The present work constitutes a case study of a qualitative nature in which it was approached about the Equoterapia, history, benefits, the development of the child with specific educational needs as a resource and technique of rehabilitation, as well as, through data collected from of the questionnaire applied to school, family and therapeutic space respondents who stated that in a year and three months of equine therapy there were results of improvements in attention, concentration; social relationships in school with teachers and colleagues; motricity and social interaction of the practitioner. Aspects that are of great importance in school performance.
\end{abstract}

Keywords: Equine Therapy, Specific Needs, School Scope.

\footnotetext{
${ }^{1}$ Faculdade de Ciências Humanas do Sertão Central (FACHUSC). Contato: edy.mila@ hotmail.com;

${ }^{2}$ Mestre em Educação em Ciências: Química da Vida e Saúde pela Universidade Federal do Rio Grande do Sul. Possui graduação em Ciências Biológicas pela Faculdade de Filosofia de Crato CE. Atualmente é Professora das Escola, Francisco Filgueira Sampaio e Professora da Faculdade De Ciências Humanas Do Sertão Central. Contato: socorrosobral@bol.com.br
}

1181 Id on Line Rev. Mult. Psic. V.12, N. 42, p. 1181-1190, 2018 - ISSN 1981-1179 Edição eletrônica em http://idonline.emnuvens.com.br/id 


\section{Introdução}

O presente estudo tem como objetivo analisar e divulgar os benefícios da equoterapia. De acordo com Cirillo (1991:01),"Equoterapia é um tratamento de reeducação motora e mental, através da prática de atividades equestres e técnicas de equitação". Essa técnica consiste na semelhança entre a passada do animal e do homem possibilitando o tratamento de praticantes com necessidades especiais. Desta forma, apresentar a importância da Equoterapia no processo ensino aprendizagem visto que promove o desenvolvimento de aspectos psicomotores, cognitivos e interação social do estudante. Considerando como justificativa que essa técnica ainda é desconhecida no âmbito escolar.

Essa pesquisa consiste num estudo de caso, com praticante da equoterapia no município de Salgueiro PE. Através abordagem qualitativa e tendo como técnica o questionário para levantamento de dados.

Dentro dessa abordagem há uma ligação entre o pesquisador e o sujeito, sendo o pesquisador aquele que busca informações para seu estudo faz interpretações referente as mesmas para divulgação do conhecimento adquirido como apoio para outras pessoas.

Durante essa pesquisa foi aplicado um questionário semiestruturado a um respondente do ambiente familiar, escolar e terapêutico, sendo este o critério adotado para escolha dos sujeitos dessa investigação. A abordagem foi realizada através de questões muito particulares, os dados levantados foram significativos nas interpretações e foram tratados a partir da contribuição de outros teóricos que fundamentaram essa temática.

A contribuição da pesquisa consiste em apresentar a importância de iniciar a Equoterapia, logo que forem identificadas as necessidades educativas especiais do praticante considerando seus benefícios e tomando como exemplo, que num período de um ano e três meses como foi revelado no estudo de caso, já podem ser visualizados resultados na melhoria da atenção concentração; relações sociais na escola com professores e colegas; motricidade e interação social. Aspectos que são de suma importância no rendimento escolar. 


\section{Fundamentação Teórica}

Equoterapia é um método terapêutico e educacional com a utilização do cavalo para promover ganhos físicos e psicológicos em pessoas com diversas deficiências, ampliando esse conceito (ANDE-BRASIL, 2004) salienta:

Equoterapiaé um método terapêutico e educacional que utiliza o cavalo dentro de uma abordagem interdisciplinar, nas áreas de saúde, educação e equitação, buscando o desenvolvimento biopsicossocial de pessoas com deficiência e/ou com necessidades especiais. Elaemprega o cavalo como agente promotor de ganhos físicos, psicológicos e educacionais (P. 40).

Os conceitos acima favorecem a compreensão da importância da equoterapia como uma forma de promover melhor o desenvolvimento de pessoas com necessidades especificas, através da relação entre homem e animal.

De acordo com Cirillo (1991:01),"Equoterapia é um tratamento de reeducação motora e mental, através da prática de atividades equestres e técnicas de equitação". Essa técnica consiste na semelhança entre a passada do animal e do homem.

O cavalo se deslocando ao passo transmite ao praticante, uma série de movimentos sequenciados e simultâneos, que têm como resultante o movimento tridimensional (DAS NEVES, 2008), percebe- se que é esse movimento tridimensional que possibilita a melhoria no estado em que se encontra o paciente.

Sendo o homem um sujeito único com qualidade específicas mesmo quando incluído dentro de uma patologia típica, torna-se importante analisar os meios que serão usados para seu tratamento. Assim, como a escolha do cavalo é essencial para o bom desenvolvimento de pessoas especiais, a nomeação de um programa em função das necessidades e potencialidades de cada praticante também é de suma importância, tornando-se necessário entender como instrumento de realização de movimentos do corpo ativo ou passivo e bem como verificar se existe interferência do peso na frequência do passo e ainda na parcela de incentivos mandados ao paciente durante a terapia.

Cabe-nos uma reflexão: A equoterapia pode ajudar na ação pedagógica? Ao questionar Severo (2006, p. 143) , afirma que: 
Para se entender os benefícios psicomotores da equoterapia no ser humano e principalmente, na criança, há necessidade de se estabelecer, à priori, que o ser humano é um produto filogenético, ontogenético e cultural, sendo o sistema nervoso, os estados psicológicos e as situações sociais, os grandes responsáveis pelas aquisições da aprendizagem e dos desempenhos comportamentais. Em segundo lugar, há necessidade de se entender que o desenvolvimento psicomotor antecede o desenvolvimento cognitivo e emotivo, segundo vários autores. Os fatores psicomotores distribuídos pelas unidades funcionais de Luria são apresentados como circuitos dinâmicos auto regulados, construídos segundo o princípio da organização vertical das estruturas do cérebro e dependentes de uma hierarquização funcional e afetiva, que ocorre em todo o desenvolvimento da criança. Todos os engramas psicomotores reunidos funcionalmente compreendem uma complexa constelação psicomotora, pois cada um contribui, particularmente, para a organização global do sistema funcional psicomotor... Educar é ajudar o ser humano com os princípios e os fundamentosdo ensino e da aprendizagem, informal e formal, na família e na sociedade, a transformar-se pelo crescimento e pelo desenvolvimento biopsicossocial em um cidadão com liberdade, felicidade e paz. (Apud BRITO, 2013, p. 10)

Desta forma, o reforço da equoterapia para a educação inclusiva, proporciona a instigação para os outros alunos, a experiência em estar no dorso de um cavalo, onde o alvo de desejo são os fins psicoterapêuticos para as crianças especiais passa a espertar nas crianças "ditas normais", a aplicação do mesmo com fins esportivos.

$\mathrm{Na}$ área da educação os benefícios da equoterapia são abundantes, pois as relações estabelecidas nas sessões entre praticante-cavalo desenvolvem a qualidade e afeição, passando ganhos de autoestima e segurança em seguida existem melhoras no senso de limite e responsabilidade. Apresenta-se também avanço na socialização e relacionamento, tendo melhorias nos quadros de timidez, nos déficits de atenção e hiperatividade e, ainda, doenças do humor.

A Equoterapia é uma ferramenta auxiliar no sistema de conhecimento na criança com transtorno de déficit de atenção e hiperatividade na escola regular, pois através da execução da mesma possibilita-se introduzir limites, há ganhos na concentração/atenção, no estímulo do aluno para o processo de ensino aprendizagem, diminuição da agressividade, aceitação de normas e regras, principalmente de autoridade do professor, ou seja estes benefícios fazem-se de extrema importância dentro do ambiente escolar.

É um momento significante na vida da criança: de exploração, aproximação das relações, afetividade, compreensão das limitações; é a descoberta das potencialidades, é momento da criança acreditar nela, nas suas capacidades de responder aos variados estímulos naturais que o meio oferece. Estes meios facilitadores implicam na interconexão e, suas 
influências externas, nesta forma de aprendizagem, sendo modificada pelo ambiente que o transforma na atividade ativa, relacionando-se com pessoas, objetos materiais e animais.

A atuação prática em equoterapia, busca responder as necessidades da criança especial, com atividade extracurricular, que suplementa na proposta pedagógica, capaz de permitir ao aluno um ambiente agradável e importante para o seu desenvolvimento. Com isso, as experiências trazidas do seu meio familiar e a prática de equoterapia, favorece, assim, com amelhora na coordenação motora fina, equilíbrio postural, desempenho nas atividades escolares, melhora na escrita e maior socialização.

Qual o cavalo ideal para a Equoterapia?

É de fundamental importância que se tenha conhecimento sobre o animal que irá utilizar, saber a sua história.Sabemos que o cavalo é um animal associativo, ou seja, todas as memórias são armazenadas em seu cérebro para sempre, podendo estas serem resgatadas a qualquer momento , isto quer dizer que se o cavalo foi maltratado por sua doma ou sofrido algum trauma ele pode reagir de forma negativa durante a terapia; por isso conhecer o animal antes de começar o tratamento é a regra principal.

Se o centro de equoterapia tem como objetivo alcançar as pessoas portadoras de deficiências físicas ou neuromotoras, o cavalo a ser escolhidotem como prioridade ter como andamento, o trote. Somente através do cavalo de trote, serão alcançados objetivos neuromotores propiciados por estímulos inerentes a este andamento, conhecido como, movimento tridimensional. O cavalo de trote tem o andamento simétrico, no trote, o joelho do cavalo nunca avança a frente de uma linha imaginaria.

É de suma importância que no centro não tem éguas, pois, a utilização da égua pode ser um problema quando possuir qualquer possibilidade de ser flertada por um cavalo garanhão durante o atendimento, para retirar esse risco, é de extrema importância utilizar somente cavalos machos e castrados, eliminando assim riscos de influências hormonais que possam haver situações inevitáveis e de difícil controle durante a sessão terapêutica.

Outro ponto bastante importante é que o cavalo não seja um animal alto,além de $1.60 \mathrm{~m}$ de altura, facilitando assim a facilidade do terapeuta ao paciente quando o mesmo desejar aplicar alguma técnica ou conduta terapêutica. $\mathrm{O}$ animal da equoterapia precisa ser um animal dócil, treinado e destinado para essa atividade; obedecendo esses critérios esse animal será de fácil manejo e assim facilitará em um tratamento com ótimos resultados.

\section{5 \\ Id on Line Rev. Mult. Psic. V.12, N. 42, p. 1181-1190, 2018 - ISSN 1981-1179} Edição eletrônica em http://idonline.emnuvens.com.br/id 
Coma função de aliar o cavalo e sua docilidade como alvo de um instrumento capaz de promover movimentos no corpo e então tratar pacientes com déficits motores este trabalho tem o proposito de analisar-se se o peso sobre o dorso do cavalo interfere na frequência de seu passo, para com isso verificar as alterações de variação do passo no decorrer dos atendimentos equoterápicos.

O único profissional que pode autorizar um paciente a participar das sessões de Equoterapia é aquele que tem formação médica, um atestado médico deverá ser solicitado junto ao encaminhamento para o tratamento equoterápico, a fim de não expor o paciente a nenhum risco (NASCHERT, 2006 P. 11).

Através desse atestado medico o paciente poderá começar o seu tratamento de forma legal e que não prejudique a sua saúde, tendo em vista que é de extrema importância que o seu responsável tenha os cuidados de ir em busca de um profissional adequado para esse tratamento.

A prática proporcionaganhos sensório-motores através de seus movimentos tridimensionais e das inflexões laterais (dissociação de cinturas) que potencializam a circuitaria sináptica evocando a modulação de tônus muscular, fazendo ajustes posturais (DE SOUZA,2009.P.41).

Esses ganhos estão relacionados aos aspectos físicos e psicológicos trabalhados nos pacientes, que adotaram a equoterapia como forma de tratar suas patologias.

“Através da experiência viva e vivida com o cavalo, a pessoa pode criar para si vários novos motivos para começar, continuar, modificar, aumentar ou permanecer na sua trajetória única e intransferível da arte de viver”.Ylna Opa (200- apud CUDO, 2002, p. 14), ao se relacionar com o cavalo o indivíduo passa a ver a vida de outra maneira, e também a enxergar os animais de outra forma, com amor e gratidão.

\footnotetext{
Animal dócil, de porte e força, se deixa montar, manusear e se transforma em um amigo do praticante, sendo o elemento mais importante e atuando como agente cinesioterapêutico, facilitador do processo ensino-aprendizagem, criando com ele relacionamento afetivo importante, proporcionando a inserção ou reinserção social, tornando-se assim personagem na vida do praticante e ponto de contato sedutor com o mundo que o rodeia (ENGEL, 1997,P.11).
}

O animal é educado para que se deixe montar, é um animal dócil e se torna amigo do seu companheiro, é ele que vai mediar o melhor desenvolvimento para a criança. Proporcionando diversas formas de carinho, gratidão e amor a seu companheiro. 


\section{Metodologia}

Essa pesquisa consistiu num estudo de caso, com praticante da equoterapia no município de Salgueiro PE., através abordagem qualitativa, com técnica do questionário para levantamento de dados, que segundo Chizzotti:

\footnotetext{
$\mathrm{Na}$ abordagem qualitativa existe "uma relação dinâmica entre o mundo real e o sujeito", onde o conhecimento não seria representado por dados isolados, já que o pesquisador interpreta e dá significado a eles. Na pesquisa qualitativa, tal pesquisador não é um relator passivo, e suas interpretações e percepções têm papéis significativos que influenciam diretamente os resultados finais. (1991, p. 79)
}

Dentro dessa abordagem há uma ligação entre o pesquisador e o sujeito, sendo o pesquisador aquele que busca informações para seu estudo faz interpretações referente as mesmas para divulgação do conhecimento adquirido como apoio para outras pessoas.

Dentre as principais técnicas de coleta de dados da pesquisa qualitativa, três predominaram neste estudo: entrevista, observação participante e questionário.

Durante essa pesquisa foi aplicado um questionário semiestruturado a um respondente do ambiente familiar, escolar e terapêutico, sendo este o critério adotado para escolha dos sujeitos dessa investigação. A abordagem foi realizada através de questões muito particulares, os dados levantados foram significativos nas interpretações e foram tratados a partir da contribuição de outros teóricos que fundamentaram essa temática.

\section{Resultados e Discussão}

Participaram do estudo de caso três respondentes, sendo um do ambiente escolar, outro do familiar e outro do terapêutico. Os quais revelaram através do questionário aplicado que num período mínimo de um ano e três meses o praticante da Equoterapia apresentou melhoria nos seguintes aspectos: atenção concentração; relações sociais na escola com professores e colegas; motricidade e interação social. E que o registro dos avanços da Equoterapia foi feito através de relatório escrito, de observação; preenchimento de ficha; aplicação de teste, entre outros, bem como a importância da Equoterapia foi avaliada pelos respondentes no processo pedagógico entre a nota 9 e 10, como detalha a tabela abaixo. 
Tabela 1 - Informações Coletadas Sobre o sujeito Praticante da Equoterapia

\begin{tabular}{|c|c|c|c|}
\hline \multicolumn{4}{|c|}{ INFORMAÇÕES COLETADAS SOBRE PRATICANTE DA EQUOTERAPIA } \\
\hline $\begin{array}{c}\text { Aspectos } \\
\text { questionados }\end{array}$ & $\begin{array}{c}\text { Proveniente da } \\
\text { Família }\end{array}$ & $\begin{array}{l}\text { Proveniente da } \\
\text { Escola }\end{array}$ & $\begin{array}{c}\text { Proveniente do } \\
\text { Terapêutico }\end{array}$ \\
\hline Faixa etária & 3 a 10 anos & 3 a 10 anos & 3 a 10 anos \\
\hline $\begin{array}{c}\text { Tempo de } \\
\text { duração da } \\
\text { Equoterapia }\end{array}$ & 1 ano e 3 meses & 1 ano e 3 meses & 1 ano e 3 meses \\
\hline $\begin{array}{l}\text { Contribuições da } \\
\text { Equoterapia no } \\
\text { processo } \\
\text { pedagógico. }\end{array}$ & $\begin{array}{c}\text { Atenção } \\
\text { concentração; } \\
\text { motricidade e } \\
\text { interação social. }\end{array}$ & $\begin{array}{l}\text { Motores } \\
\text { Psicossociais } \\
\text { cognitivos }\end{array}$ & $\begin{array}{c}\text { Atenção } \\
\text { concentração; } \\
\text { motricidade e } \\
\text { interação social. }\end{array}$ \\
\hline $\begin{array}{l}\text { Importância da } \\
\text { Equoterapia numa } \\
\text { escala de } 1 \text { a } 10\end{array}$ & 10 & 9 & 10 \\
\hline $\begin{array}{c}\text { Forma do registro } \\
\text { dos avanços do } \\
\text { praticante da } \\
\text { Equoterapia }\end{array}$ & Observação & $\begin{array}{c}\text { Observação; relatório } \\
\text { escrito; } \\
\text { preenchimento de } \\
\text { ficha; aplicação de } \\
\text { testes }\end{array}$ & Observação \\
\hline
\end{tabular}

Fonte: autoras do estudo, 2018

Corrobora Souza, MB. Silva. 2015, p. 4-22 e Espíndula, 2008 quando afirmam que a Equoterapia promove [...]melhora nas habilidades sociais, cognitivas, sensoriais e motoras promovendo fortalecimento e alongamento muscular, ajustes tônicos e posturais, equilíbrio, coordenação motora, e diminuição dos padrões estereotipados. Nesse sentindo esse estudo contribui na melhoria do ensino aprendizagem ao ser divulgado nos ambientes escolares.

Em se tratando de Equoterapia, é necessário observar que os benefícios devem ser registrados e como um todo, uma vez que afeta de forma global o desenvolvimento do praticante, interferindo direta ou indiretamente nos objetivos que desejamos alcançar 


\section{Considerações Finais}

A Equoterapia tem sido indicada por vários profissionais da área da saúde e em educação, como uma ferramenta complementar, no tratamento de diferentes transtornos e patologias. Seu objetivo é o de conseguir ganhos físicos, psicológicos, emocionais e sociais. Nesse sentido, por meio do programa de intervenção com Equoterapia, buscou-se proporcionar às crianças com dificuldade de aprendizagem oportunidades para que fortalecessem as diferentes áreas do desenvolvimento motor, cognitivo e social, com o intuito de melhorar seu desempenho escolar e também habilidades sociais importuníssimas para o seu convívio no ambiente escolar e familiar. Outro fato que merece destaque é a importância de associar as sessões de Equoterapia, atividades lúdicas complementares, principalmente.

Quando o objetivo do estudo é promover ganhos no aprendizado. A participação dos professores, pais e responsáveis por essas crianças, é fundamental durante todo o desenvolvimento do estudo. Tais informações que eles fornecem, irão subsidiar a elaboração de novas pesquisas em saúde e em educação, favorecedoras de suporte aos alunos com tais dificuldades.

Finalmente este estudo comprova que benefícios físicos, cognitivos e sociais interferem diretamente no desempenho do praticante em seu ambiente escolar, promovendo assim benefícios na esfera educacional de crianças com necessidades educativas especiais, assim sendo quantos mais for divulgado aos educadores maior será a inclusão social.

\section{Referências}

ANDE (1999). Disponível em: <http://www.equoterapia.com.br/o_que_e- -definicao.php>. ANDE-BRASIL - ASSOCIAÇÃO NACIONAL DE EQUOTERAPIA. Curso Básico de equoterapia. Brasília, 2003. Disponível em: <http://www.equoterapia.org.br/site/equoterapia.php>.

BRITO, M. C. G. As contribuições da equoterapia na educação inclusiva. 2013. Disponível em: <http://equoterapia.org.br/media/artigos-academicos/ documentos/18082259.pdf>. Acesso em: 11 abr. 2016. 
CHIZZOTTI, A. Pesquisa em ciências humanas e sociais. São Paulo: Cortez, 1991.

CIRILLO. Entrevista do mês de Julho/08 - Cel. Cirillo - ANDE - BRASIL. EQUOTERAPIA: CUDO, C. A importância da motivação para a vida e como meio facilitador para resgatar a auto-estima. In: CONGRESSO BRASILEIRO DE EQUOTERAPIA, 2., 2002, Jaguariúna. Anais... Brasília: Ande-Brasil, 2002. p. 11-15.

ENGEL, B. T. Indications and contraindications for hippotherapy Indications and contraindications for hippotherapy and equine-assisted occupational, physical or speech therapy. In: ENGEL, B. T. Therapeutic riding two strategies for reabilitation. Durango: Ommipress, 1997. p. 35-42.

ESPINDULA, AP. Efeitos da equoterapia em praticantes autistas. [tese]. Uberaba (MG): Universidade Federal do Triângulo Mineiro; 2008. Disponível em: http://livros01.livrosgratis.com.br/cp073999.pdf

NASCHERT, E. G. Equinoterapia: larehabilitación por médio delcaballo. México: Trillas, 2006. Revista Eletrônica Inspirar [recurso eletrônico] - Curitiba: Centro de Estudos, Pesquisa e Extensão em Saúde, 2009- Bimestral, v. 1, n. 3, nov./dez. 2009.-Periódicos.

NEVES, Danusa, G. et al. A Semelhança dos Movimentos do Andar Natural do Ser Humano com os Movimentos da Andadura Natural do Cavalo: Um Trabalho Extensionista do NEQUI. Seminário promovido pelo NEQUI. S.d.

SOUZA, Jerusa de. C. Equoterapia: Tratamento Especializado para Pacientes com Lesão Medular.

SOUZA, MB. SILVA, PLN. Equoterapia no tratamento do transtorno do espectro autista:a percepção dos técnicos. Rev. Ciênc. Conhecimento. 2015; 9(1). p. 422.Disponível://cienciaeconhecimento.com.br/Arquivos/Edi\%C3\%A7\%C3\%A3o\%202015/S ouza\%20BM_912015.pdf

Como citar este artigo (Formato ABNT):

BARROS, Edmila Lima de; SOBRAL, Maria do Socorro Cecílio. A Relevância da Equoterapia no Desenvolvimento de Crianças com Necessidades Especificas no Âmbito Escolar. Id on Line Rev.Mult. Psic., 2018, vol.12, n.42, p. 1181-1190. ISSN: 1981-1179.

Recebido: 25/06/2018;

Aceito: $29 / 10 / 2018$ 